quod hodie etiam manu sua exaratum extat, causam Catholicorum semel atque iterum Cicilio, Angliæ Thesaurario, cognato suo prodidisse putatur, a cuius filio, qui modo Reginæ à secretis est omniaque gubernat, curatum esse, suspicantur multi quod explorandi causa Romam sit missus.

Postremus uero senex iracundæ naturæ, qui ex ministro olim Caluiniano factus sacerdos, multa scandalosè ex bile contra socios presb'ros in carcere gessit, idque tam uerbis quam pugno, et ex ipsiusmet literis constat eum ualde perfide cum ipsa Regina ac Consiliriss contra viros multos Cath ${ }^{\mathrm{cos}}$ egisse.

19. Methodus expeditissima qua possint facillime discerni turbarum et controuersiarum Architecti in Anglia.

54, f. 140.

Citatus, et iuramenti religione astrictus, P. Personius ad hæc quæ sequuntur capita nudè et apertè sine ambagibus aut ambiguitate ut respondeat magna nos liberabit molestia, fontesque omnes et scaturigines calamitatum et controuersiarum nostrarum ita reddet conspicuas, ut non de morbo, sed de remedio (tali facto examine) Sanctitati V'ræ sit laborandum.

\title{
I CAP.
}

Cum in Angliam à Gregorio $13^{\circ}$ Anno 80. fuerit missus, an in mandatis habuerit rebus politicis se immiscere, et quousque in ijs progressus sit, utrum à superioribus nocatus ante finitum biennium Angliam reliquerit, in Gallijs personatus in habitu seculari, extra Collegij sui septa uixerit, Hispaniamque eodem ornatu aduolauerit

a Tierney (vol. iii. p. olvii.) gives an analysis of another memorial, which he calls "an extraordinary document," drawn up by Parsons for the information of the pope and cardinals, and entitled "An account of the morals of some of the principal appellants." Charges of unchastity, drunkenness, violence, and treason are there urged against several priests in greater detail and with much asperity. Tierney prints also the text of a "Memorial against the Appellants" from a rough draft in the handwriting of Parsons, presented in the name of the Archpriest's agents, April 1602, dealing mainly with the "ambition," "sedition" and "dissolute lives " of his opponents: 
rebusque politicis totus uacauerit, paratos se reliquisse ad arma Cath. animos egregie simulans, et hoc comento ad Principum aulas et aures sibi muniens viam? an quæ Religionem spectassent negotia et seminariorum cura et sollicitudo non multo melius et decentius in suo habitu suisque monasterijs perfici et pertractari potuissent?

Interrogandus est qua auctoritate Regnum Angliæ quasi venale tot principibus obtulerit, Comiti Darbiensi alijs ad eum missis, alijs destinatis ad eundem nuncijs, Duci Parmensi, Comiti Arundeliæ, et Regi Catholico eiusque fliæe.

Qua auctoritate librum suum de Success ${ }^{\text {ne }}$ Comiti Essexiæ dedicauit, eique epistolam nuncupatoriam præfixit.

54, f. 140 Qua auctoritate libros scripserit de iure Regni in genere et de Regni Angliæ Success ${ }^{\text {ne }}$, quorum primus regibus et monarchis non potest non esse ingratissimus licet uerissimus, secundus multos Principes et Primarios uiros graui affecit iniuria, omnes Regij sanguinis Principes, preter unicam Philippi Reginam aliqua insigni ignominia notauit, omnes competitores ad arma et uim animaverit.

Qua auctoritate libros uarios meram politiam sapientes in refectorijs legi iusserit.

Qua auctoritate alumnos seminariorum titulo Hispaniæ subscribere coëgerit, recusantes uero male mulctauerit.

Qua auctoritate librum quem nocant Reformat ${ }^{\text {nis }}$ scripserit, in refectorijs legi mandauerit, cuius summa est ut in Anglia mutentur omnia, leges, consuetudines, iura, census, uictus, Prelatorum hospitalitas, nobilium auctoritas; quæ omnia Tyrannidem uel præcedunt uel sequuntur.

Qua fretus anctoritate libros alios promulgauerit, alios ipse conscripserit, Reginamque Angliæ eosque præcipuè, qui ad clauum Reip $^{c 8 s}$ sedebant, adeo acritèr et acerbe perstrinxerit, ut inde irritati in Catholicorum cædem et perniciem nouas leges nouaqne supplicia inuenirent.

Qua fretus auctoritate apud Regem Catholicum fictis et fucatis 
rationibus et relationibus de Catholicorum paratis animis ad res innouandas de inuadenda et subiuganda Anglia egerit, Catholicas vana spe Hispaniæ classis per multos annos lactauerit, Regemque Catholicum ad uarias expeditiones, non sine magno Regis damno et dispendio, adegerit.

Qua auctoritate libellum famosum in Lecestrensem refertum hæresibus et sermonibus impudicis in persona heretici scripserit, alium etiam in magnum Angliæ Thesaurarium diuulgari curauit, ex quibus nihil aliud commodi sperari potuit quam ut illi animo morem gereret, et maiorem in fratres persequutionem excitaret.

Qua anctoritate expeditiones illas duas anni 96. et 97. et illam tertiam anni 1601 Hibernicam tam grauiter et strenue sollicitauit, Regemque Catholicum quasi inuitum imposturis suis ad illas suscipiendas adegit, sacerdotes insuper et Jesuitas Anglos et Hibernos miserit, cum res militaris nullo modo studiorum uel missionum suarum sit finis.

Qua auctoritate Holtum, Cresunellum, et Balduuinum in Belgijs et in Hispanijs ad res politicas et Regnorum et diadematum diuisiones tractandas reliquit.

Qua auctoritate Standisseum, Burleum, Fitzarbertum, Rolstunum, dum tumultus Gallici urgerent, tanquam exploratores suos in diuersas Galliæ partes miserit, Regis sumptu et Regis nomine ipsius seruientes uoluntati.

Qua auctoritate $\mathrm{ab}$ ipso uel à Cresumello uel ab ntroque fuerit missus Colstonus ad Comitem Essexire literas portans, tum ad Reginam tum ad alios eius senatores, officij et affectionis plenissimas, has quidam palàm, clanculum uero ad C'omitem alias quæ illum ad regnum capessendum animaret. Hæc sunt quæ communiter in $\mathrm{P}$. Personium obijciuntur, de quibus si se coram iudice iuratus purgauerit magna dabitur Catheis omnibus satisfactio, sin minus magna de reliquis omnibus eius actionibus suspitio.

Quod si confessione propria aut prolatis chirographis aut iuratís testibus constiterit P. Personium in his omnibus esse reum, 54; t. 1416. causam esse totius diuisionis, suspecta debent esse pari ratione 
omnia quæ $S^{\text {ti }}$ V'ræ suggerit de creatione Archipr. et de illa forma Regiminis instituenda, quam tanquam in Ecclesia Dei nouam et inauditam ad pacem inter Ecc ${ }^{\mathrm{los}}$ stabiliendam ineptam æogrè admiserunt nonnulli ex precipuis sacerdotibus, quod facile animaduerterant auctoritatem illam nomine tenus penes Archipresbyterum esse, re autem ipsa penes Personium et Jesuitas, ut ipsi sine inuidia artificiose quæ velint in deprimendis et aftigendis illis statuant, qui non sine patriæ periculo et animarum dispendio, ferro et flamma, et externo milite rem geri, et plantari posse fidem, liberè profitentur et demonstrant : uirtute vero, humilitate, patientia, morte, et plantari et rigari et renouari ad fidem Regna, et solere et debere predicant, neque dari posse exemplum ubi armis restituta fuerit religio.

Huc igitur redeunt omnia Sanct ${ }^{m e}$ P. ut qui Apostolico more, sine vi, sine strepitu, sine tumultu, pacifice, patientèr, et modestè conuersionem Angliæ et animarum messem tractari voluerunt, quique hisce tam uiolentis motibus et conatibus $P$. Personij ubiuis restiterunt pro factiosis habiti sint, fide et auctoritate apud exteros Principes exuti, et causæ publicæ et conuersioni Angliæ inimici sint habiti; cum in confesso sit, et persecut ${ }^{\mathrm{ni}}$ pabulum et animarum conuersioni impedimentum, et factionibus, et dissensionibus fomentum has Personij technas et tragedias præbuisse.

54, f. 142.

20. Oratio exhibita $S^{m o}$ pro Rebus Catholicorum in Anglia. ${ }^{a}$

Cum nihil sit quod Sanc ${ }^{\text {ti }}$ V'ræo gratiùs aut optatius possit euenire quam qua pro Catholicorum Anglorum salute pace et consolatione dicta, facta, et constituta sunt cum totum Ecclesiæ Angl ${ }_{\text {: }}$ corpus partesque singulas paterno affectu tenerrimè prosequaris, speramus fore aures illas sanctiss ${ }^{a s}$ et purgat ${ }^{\text {mas }}$ quæ hereticis, schismaticis, sicarijs, et sacrilegis pro illorum salute plerumque patent, fliorum suorum lachrymis et lamentis non posse occludi, petimus ergo, ut uera narrantibus et iusta postulantibus, non inimicorum

- Presented by Cecil at his audience of the pope, 17 or 19 June. 